\title{
Application of Fenton reagent and adsorption as advanced treatment processes for removal of Maxilon Red GRL
}

\author{
Çiner F.* \\ Nigde Omer Halisdemir University, Department of Environmental Engineering, Nigde, 51240, Turkey \\ Received: 28/04/2017, Accepted: 25/08/2017, Available online: 01/12/2017 \\ *to whom all correspondence should be addressed: e-mail: fciner@ohu.edu.tr
}

\begin{abstract}
In this paper, the removal of Maxilon Red GRL by adsorption onto raw soil sample known as Niğde (Bor) grape molasses soil and $\mathrm{Fe}^{+2} / \mathrm{H}_{2} \mathrm{O}_{2}$ reagent as advanced treatment processes were investigated. The effects of various experimental parameters such as initial $\mathrm{Fe}^{+2}$ and $\mathrm{H}_{2} \mathrm{O}_{2}$ concentrations, $\mathrm{pH}$, temperature, contact time, initial adsorbent dose, and initial dye concentration on adsorption and Fenton process efficiencies were studied in a batch reactor. The adsorption experimental data were modeled by Langmuir and Freundlich isotherm models. The data fitted well with the Langmuir isotherm $\left(R^{2}>0.99\right)$. The optimum conditions had been determined and found that efficiency of decolorization obtained after $20 \mathrm{~min}$ of reaction, was about $99.4 \%$ for Fenton process.
\end{abstract}

Keywords: adsorption, advanced oxidation process, decolorization, Fenton process, maxilon red.

\section{Introduction}

Wastewater effluents from different industries such as textile, food processing, cosmetics, rubber and plastics contain various kinds of synthetic dyes (Chiou et al., 2004). The textile industry is a water-consuming and heavily polluting industry (Jia et al., 2017). Therefore, potentially releasing xenobiotics from washing and rinsing procedures during finishing processes (Lofrano et al., 2016). The main sources of wastewater generated by the textile industry originate from dyeing and finishing operations (Şahinkaya, 2013; Kumari et al., 2017). The dyeing wastewater is potentially toxic and poorly biodegradable, which results in a tremendous threat to aquatic organisms (Jia et al., 2017). In this context, wastewater management receives a great deal of attention with various methods being proposed for discharge hazard estimation via ecotoxicological results (Libralato et al., 2010). Textile wastewater is characterized by high chemical oxygen demand (COD), biological oxygen demand (BOD), alkalinity and total dissolved solids (TDS) (Hayat et al., 2015). Among the different classes of textile dyes the basic ones have high brilliance and intensity of colors and are highly visible even in a very low concentration (Aksu, 2005). Disposal of dyes in precious water resources must be avoided and for that various treatment, technologies are in use (Gupta and Suhas,
2009). Various physical, chemical and biological methods such as adsorption, photolysis, chemical coagulation, chemical oxidation and reduction, electrochemical precipitation have also been used for the removal of dyes from wastewater in the past few decades (Hayat et al., 2015; Jia et al., 2017). However, all of these methods suffered with one or another limitation, and none of these were successful in removing color from the wastewater completely (Doğan et al., 2009).

Adsorption occupies a prominent place and the use of inexpensive and one of the most efficient methods of removing pollutants from wastewater and provides an attractive alternative treatment, especially if the adsorbent is inexpensive and readily available (Gupta and Suhas, 2009; Karaoglu et al., 2009). Adsorption on solid surface is being growing interest in this field because of its lower price (Nandi et al, 2009). To lower the cost of wastewater treatment, many researchers have focused on finding the low-cost alternative adsorbents (Weng et al., 2009).

Recently, AOPs have received considerable attention because it is possible to degrade organic compounds and color from wastewaters (Schrank et al., 2007; Ertugay and Acar, 2017). The Fenton process is an extremely attractive option to degrade organic compounds present in wastewater due to the low-operating cost and low toxicity of the reagents. The oxidation process involves the reaction of $\mathrm{Fe}^{2+}$ salts with $\mathrm{H}_{2} \mathrm{O}_{2}$ to produce theradical ${ }^{\circ} \mathrm{OH}$, considered the second strongest oxidizing agent after fluorine, with a standard reduction potential of $2.8 \mathrm{~V}$. In this case, $\mathrm{Fe}^{2+}$ ions act as a catalyst for the formation of the radical ' $\mathrm{OH}$. Fenton's reaction occurs at $\mathrm{pH}$ values between 2 and 4, and the reaction products are carbon dioxide, water, and inorganic salts (Almazán-Sánchez et al., 2014).

In the present study, the removal of Maxilon Red GRL (MR $\mathrm{GRL}$ ) from aqueous solutions by adsorption onto raw soil sample known as Niğde (Bor) grape molasses soil and $\mathrm{Fe}^{2+} / \mathrm{H}_{2} \mathrm{O}_{2}$ reagent as advanced treatment processes were studied. The effect of different parameters such as initial $\mathrm{Fe}^{2+}$ and $\mathrm{H}_{2} \mathrm{O}_{2}$ concentrations, $\mathrm{pH}$, temperature, contact time, initial adsorbent dose, and initial dye concentration on adsorption and Fenton process efficiencies were investigated. 


\section{Materials and Methods}

\subsection{Materials}

All chemicals used were of analytical grade and were used without further purifications. The basic dye was supplied from carpet industry in Niğde, Turkey. Stock solution of MR GRL dye contains $500 \mathrm{mg}$ dye/L and was prepared by ultrapure distilled water. This stock solution was diluted in accurate proportions to produce solutions of different initial concentrations. The structure of the dye studied is shown in Fig. 1.

The raw soil sample known as Niğde (Bor) grape molasses soil was used for the adsorption of basic dye from aqueous solutions. This soil which consists of mostly calcite was used for sedimentation to make grape molasses. The solid sample was ground and sieved to $0.075-2 \mathrm{~mm}$ particle size.

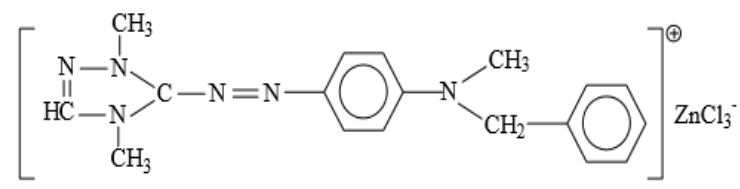

Figure 1. Structure of MR GRL dye.

\subsection{Analytical Methods}

A calibration curve was achieved using the standard solutions of MR GRL basic dye with different concentrations in the range of $0.5-50 \mathrm{mg} / \mathrm{L}$. The efficiency of the proposed process was evaluated by monitoring MR GRL removal after measuring absorbance at $\lambda \max =530 \mathrm{~nm}$. After sampling the reaction was continued. The dye removal efficiency of MR GRL was calculated as follows:

$$
\text { \% Dye removal }=\left(1-\frac{C_{t}}{C_{0}}\right) 100
$$

where $C_{o}$ is the initial concentration of the MR GRL basic dye, and $C_{t}$ is its concentration at reaction time $t$ ( $\mathrm{min}$ ).

\subsection{Fenton Experiments}

The Fenton process experiments were conducted by using jar test method. The operating parameters included dosages of $\mathrm{H}_{2} \mathrm{O}_{2}$ and $\mathrm{Fe}^{+2}$, $\mathrm{pH}$ value, temperature, initial dye concentration and oxidation time. Every beaker was first filled with $200 \mathrm{ml}$ of dye wastewater sample, and the $\mathrm{pH}$ of the reaction mixture was adjusted by adding $1 \mathrm{~N} \mathrm{H}_{2} \mathrm{SO}_{4}$ or $1 \mathrm{~N} \mathrm{NaOH}$ solution and was measured by a $\mathrm{pH}$-meter (InoLab-IDS Multi 940). The dye oxidation was achieved by Fenton's reagent which was composed of a mixture of $\mathrm{FeSO}_{4} .7 \mathrm{H}_{2} \mathrm{O}$ and $\left.\mathrm{H}_{2} \mathrm{O}_{2} 36,5 \%, w / w\right)$. The necessary quantities of $\mathrm{Fe}^{2+}$ and $\mathrm{H}_{2} \mathrm{O}_{2}$ were added simultaneously in the dye solution and the process was proceeded with rapid mixing of wastewater sample at $150 \mathrm{rpm}$ for $2 \mathrm{~min}$, slow mixing at $30 \mathrm{rpm}$ for $20 \mathrm{~min}$, and then maintaining standstill for $30 \mathrm{~min}$. The supernatant samples were filtered $0.45 \mu \mathrm{m}$ filter paper and analysed for color analyses.

\subsection{Batch Adsorption Experiments}

Batch adsorption experiments were carried out $100 \mathrm{ml}$ capacity of erlenmeyer with $50 \mathrm{ml}$ of dye solution for different contact times by using shaker. The effects of $\mathrm{pH}$ (2 to 10), initial dye concentration (5-100 mg/l), amount of grape molasses soil (1-15 g/L), contact time (0-1440 $\mathrm{min}$ ) were performed onto adsorption efficiency. The suspensions were mixed at $150 \mathrm{~min}$ at constant temperature $\left(30^{\circ} \mathrm{C}\right)$ in a shaker at $150 \mathrm{rpm}$ until equilibrium was reached. The $\mathrm{pH}$ of the solutions was adjusted to the required value by adding either $1 \mathrm{~N} \mathrm{H}_{2} \mathrm{SO}_{4}$ or $1 \mathrm{~N} \mathrm{NaOH}$ solution.

After equilibrium, the final concentration $\left(C_{e}\right)$ was measured using absorbance values with a Hach-Lange Model spectrophotometer and compared with the absorbance value of the initial solutions $\left(C_{0}\right)$ The absorbance was measured at $530 \mathrm{~nm}$. The amount of dye adsorption per unit mass of grape molasses soil at equilibrium qe $(\mathrm{mg} / \mathrm{g})$ was calculated by the following equation:

$$
q_{e}=\frac{\left(C_{0}-C_{e}\right) V}{W}
$$

where $V$ is the volume of the dye solution $(\mathrm{mL})$ and $W$ is the weight of adsorbent $(\mathrm{g})$ added to volume $\mathrm{V}$.

\section{Results and Discussion}

\subsection{Fenton Experiments}

The $\mathrm{pH}$ of the solution is a very important parameter for Fenton process, which controls the production rate of hydroxyl radical and the concentration of $\mathrm{Fe}^{2+}$. Fig. 2 demonstrates the $\mathrm{pH}$ effect on the color removal of $\mathrm{MR}$ GRL by Fenton oxidation with a fixed amount of $100 \mathrm{mg} / \mathrm{L}$ MR GRL, $100 \mathrm{mg} / \mathrm{L} \mathrm{Fe}^{+2}$ and $200 \mathrm{mg} / \mathrm{L} \mathrm{H}_{2} \mathrm{O}_{2}$.

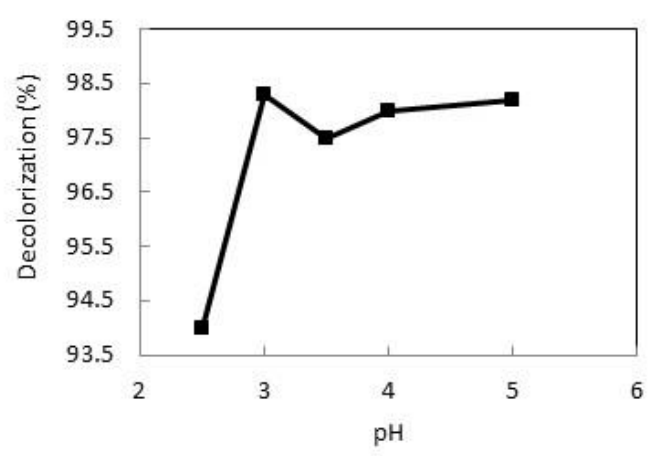

Figure 2. Effect of $\mathrm{pH}$ on decolorization of MR GRL during Fenton oxidation treatment.

Reaction conditions: $\left[\mathrm{H}_{2} \mathrm{O}_{2}\right]_{0}=200 \mathrm{mg} / \mathrm{L},\left[\mathrm{Fe}^{2+}\right]_{0}=100 \mathrm{mg} / \mathrm{L}$, $[\text { Dye }]_{0}=100 \mathrm{mg} / \mathrm{L}, \mathrm{t}=20 \mathrm{~min}$, and temperature $=25 \pm 1^{\circ} \mathrm{C}$

To find the optimal $\mathrm{pH}$ of reaction mixture, a series of experiments were conducted at different $\mathrm{pH}$ values 2.0, 3.0, 3.5, 4.0 and 5.0. The results indicated that the degradation of MR GRL was significantly influenced by the $\mathrm{pH}$ of the solution and the optimal solution $\mathrm{pH}$ is about 3.0 giving a yield equal to $98.3 \%$. These results agree with 
several studies already carried out (Bousla et al., 2010). The color removal efficiency increases from 94.4 to $98.3 \%$ as a consequence of the $\mathrm{pH}$ value increase from 2.0 to 3.0 within $20 \mathrm{~min}$.

To see the role of initial concentration of $\mathrm{Fe}^{2+}$ on the yield of MR GRL decolorization by the Fenton process and to determine the most appropriate concentration of $\mathrm{Fe}^{2+}, \mathrm{a}$ series of experiments were conducted with different concentrations of $\left[\mathrm{Fe}^{+2}\right]_{0}$ from 50 to $150 \mathrm{mg} / \mathrm{L}$. The results obtained are presented in Fig. 3 and the highest decolorization efficiency $(98 \%)$ was recorded at $\left[\mathrm{Fe}^{2+}\right]_{0}$ value of $150 \mathrm{mg} / \mathrm{L}$ and $20 \mathrm{~min}$ reaction time. Many researchers have reported that the use of a much higher concentration of $\mathrm{Fe}^{2+}$ could lead to the self-scavenging of $\mathrm{OH}^{\bullet}$ radical by converting it to hydroxyl ions during oxidation of $\mathrm{Fe}^{2+}$ (Hameed and Lee, 2009).

$$
\mathrm{OH}+\mathrm{Fe}^{2+} \rightarrow \mathrm{Fe}^{3+}+\mathrm{OH}^{-}
$$

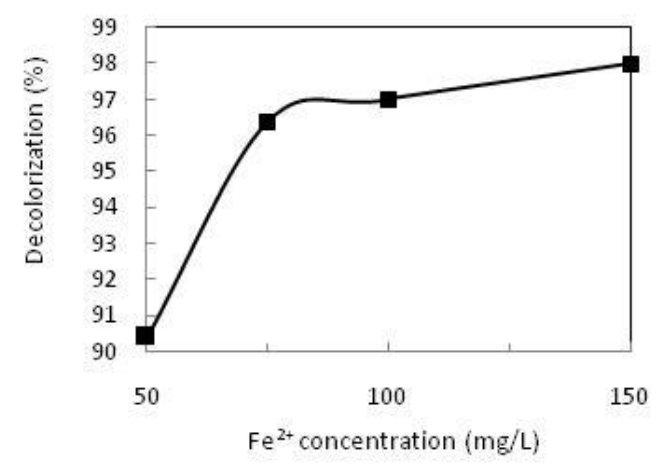

Figure 3. Effect of $\mathrm{Fe}^{2+}$ concentration on decolorization of MR GRL during Fenton oxidation treatment.

Reaction conditions: $\left[\mathrm{H}_{2} \mathrm{O}_{2}\right]_{0}=200 \mathrm{mg} / \mathrm{L}$, [Dye $]_{0}=100 \mathrm{mg} / \mathrm{L}$, $\mathrm{pH}=3.0, \mathrm{t}=20 \mathrm{~min}$, and temperature $=25 \pm 1^{\circ} \mathrm{C}$

Oxidation of dyes by the Fenton process is carried out by $\mathrm{OH}^{\bullet}$ radicals that are directly produced from reaction between $\mathrm{H}_{2} \mathrm{O}_{2}$ that plays the role of an oxidizing agent and $\mathrm{Fe}^{2+}$.

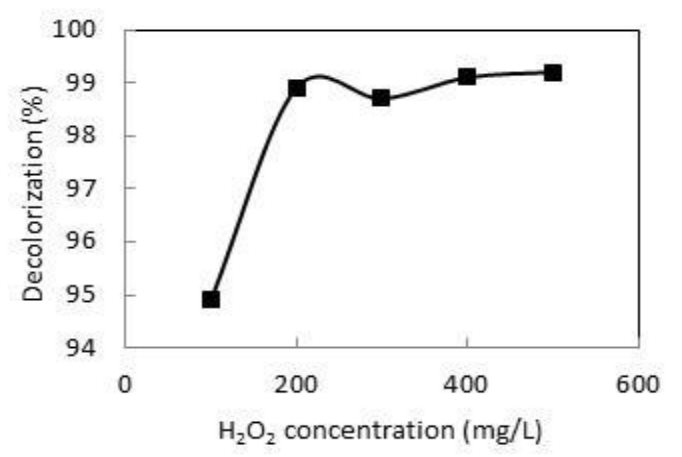

Figure 4. Effect of $\mathrm{H}_{2} \mathrm{O}_{2}$ concentration on decolorization of MR GRL during Fenton oxidation treatment. Reaction conditions: $\left[\mathrm{Fe}^{2+}\right]_{0}=150 \mathrm{mg} / \mathrm{L}$, [Dye $]_{0}=100 \mathrm{mg} / \mathrm{L}, \mathrm{pH}=3.0$, $\mathrm{t}=20 \mathrm{~min}$, and temperature $=25 \pm 1^{\circ} \mathrm{C}$
To determine the concentration of $\mathrm{H}_{2} \mathrm{O}_{2}$ giving the maximum MR GRL decolorization efficiency, experiments were conducted, and results obtained are represented in Fig.4. The decolorization efficiency increased from 94.9 to $99 \%$ because of increasing $\mathrm{H}_{2} \mathrm{O}_{2}$ dosage from 100 to 500 $\mathrm{mg} / \mathrm{L}$ at $20 \mathrm{~min}$. This can be explained by the effect of $\mathrm{OH}^{\bullet}$ radicals produced additionally (Hameed and Lee, 2009).

The study of the initial concentration effect of MR GRL dye on the efficiency of the decolorization was conducted from concentration of $50 \mathrm{mg} / \mathrm{L}$ to $500 \mathrm{mg} / \mathrm{L}$, while maintaining $\mathrm{pH}, \quad\left[\mathrm{Fe}^{+2}\right]_{0}, \quad\left[\mathrm{H}_{2} \mathrm{O}_{2}\right]_{0}$, reaction time and temperature constant at $3.0,150,200 \mathrm{mg} / \mathrm{L}, 20 \mathrm{~min}$ and $25 \pm 1{ }^{\circ} \mathrm{C}$, respectively. Fig.5, shows the effect of [dye]0 on its decolorization by Fenton process.

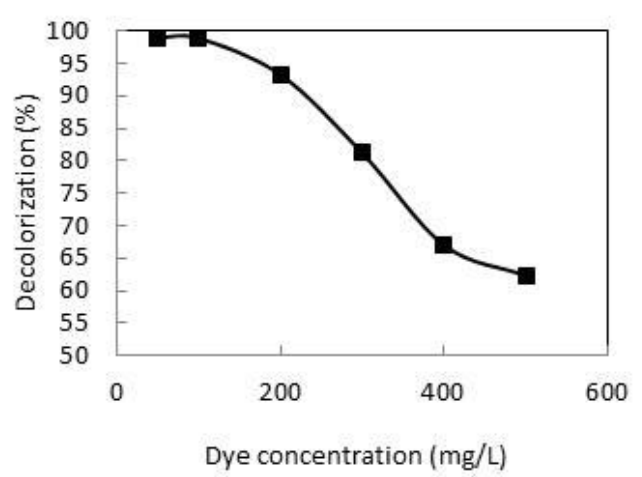

Figure 5. Effect of initial dye concentration on decolorization of MR GRL during Fenton oxidation treatment. Reaction conditions: $\left[\mathrm{Fe}^{2+}\right]_{0}=150 \mathrm{mg} / \mathrm{L}$,

$\left[\mathrm{H}_{2} \mathrm{O}_{2}\right]_{0}=200 \mathrm{mg} / \mathrm{L}, \mathrm{pH}=3.0, \mathrm{t}=20 \mathrm{~min}$, and temperature $=25 \pm 1^{\circ} \mathrm{C}$

The reaction time was varied between 5 and $60 \mathrm{~min}$. The initial $\mathrm{pH}$, the $\mathrm{H}_{2} \mathrm{O}_{2}$ dose, the $\mathrm{Fe}^{+2}$ dose and the initial $\mathrm{MR}$ GRL were kept constant at 3, 200, 150 and $100 \mathrm{mg} / \mathrm{L}$, respectively. The optimum reaction time was determined to be $20 \mathrm{~min}$. In $20 \mathrm{~min}$, the supplied $\mathrm{H}_{2} \mathrm{O}_{2}$ was probably almost completely consumed as shown in Fig. 6 .

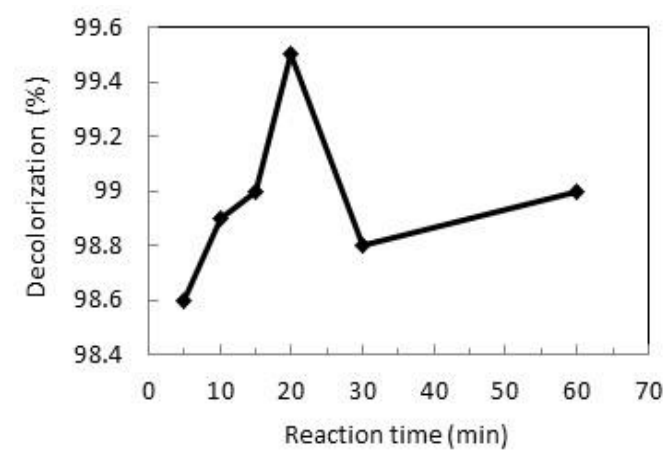

Figure 6. Effect of reaction time on decolorization of MR GRL during Fenton oxidation treatment. Reaction conditions: $\left[\mathrm{Fe}^{2+}\right]_{0}=150 \mathrm{mg} / \mathrm{L},\left[\mathrm{H}_{2} \mathrm{O}_{2}\right]_{0}=200 \mathrm{mg} / \mathrm{L}, \mathrm{pH}=3.0$, and temperature $=25 \pm 1{ }^{\circ} \mathrm{C}$

Temperature affects the reaction between $\mathrm{H}_{2} \mathrm{O}_{2}$ and $\mathrm{Fe}^{2+}$ and therefore, it should influence the kinetics of dyes 
decolorization (Bouasla et al., 2010). Experiments were performed by varying the temperature from 25 to $50{ }^{\circ} \mathrm{C}$. From Fig. 7, it can be seen that decolorization efficiency of MR GRL determined from 98.8 to $99 \%$ because of increasing temperature within 20 min of reaction time.

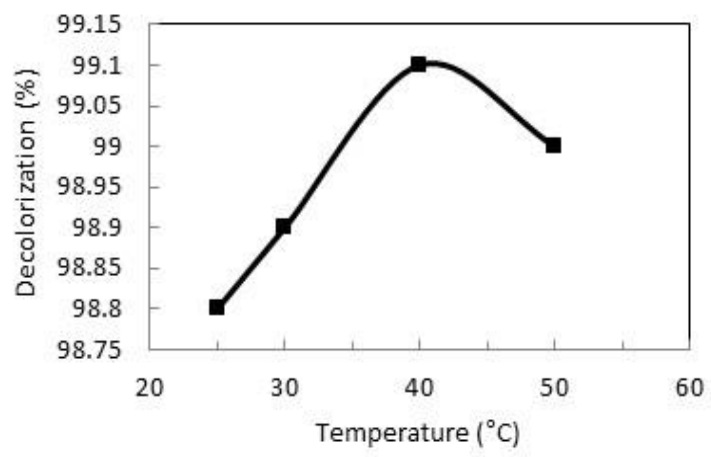

Figure 7. Effect of temperature on decolorization of MR GRL during Fenton oxidation treatment.

Reaction conditions: $\left[\mathrm{Fe}^{2+}\right]_{0}=150 \mathrm{mg} / \mathrm{L},\left[\mathrm{H}_{2} \mathrm{O}_{2}\right]_{0}=200 \mathrm{mg} / \mathrm{L}$, $\mathrm{pH}=3.0$.

\subsection{Batch Adsorption Experiments}

The initial $\mathrm{pH}$ of the aqueous solution plays an important role in the adsorption capacity (El-Sayed et al., 2013). The effect of initial $\mathrm{pH}$ on removal of MR GRL from aqueous solutions was investigated by varying the $\mathrm{pH}$ range of 2.010.0 at $30^{\circ} \mathrm{C}$ temperature for 150 min contact time. In this study, $\mathrm{pH}$ did not importantly effect the dye removal and adsorption capacity (Fig. 8). Therefore, all adsorption experiments were performed at natural $\mathrm{pH}$ of dye solutions.

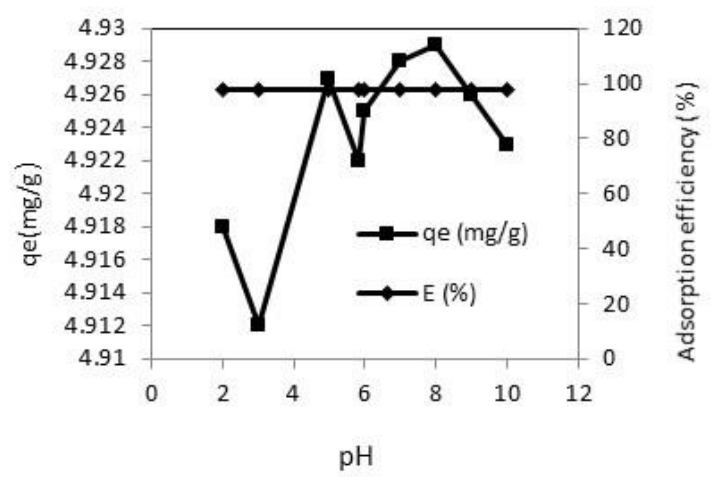

Figure 8. Effect of $\mathrm{pH}$ on MR GRL adsorption capacity. Experimental conditions: [Dye $]_{0}=50 \mathrm{mg} / \mathrm{L}$, $[\text { Adsorbent }]_{0}=10 \mathrm{~g} / \mathrm{L}, \mathrm{t}=150 \mathrm{~min}$.

In order to study the effect of adsorbent dose on dye removal by grape molasses soil was performed in a range of 1-15 g/L under the conditions specified and the results are given for removal efficiency (\%) and the amount of removed per unit weight of adsorbent (qe) in Fig. 9. An increase in the adsorbent dose from 1 to $15 \mathrm{~g} / \mathrm{L}$ resulted in a decrease of the qe from 19.4 to $3.2(\mathrm{mg} / \mathrm{g})$.
The effect of initial dye concentration on the percentage color removal of the dye was investigated at different initial dye concentrations $5,10,20,30,40,60$, and $100 \mathrm{mg} / \mathrm{L}$ using optimum $\mathrm{pH}$ and adsorbent dose. Results show that incresed initial MR GRL concentration led to increased MR GRL adsorption (Fig. 10).

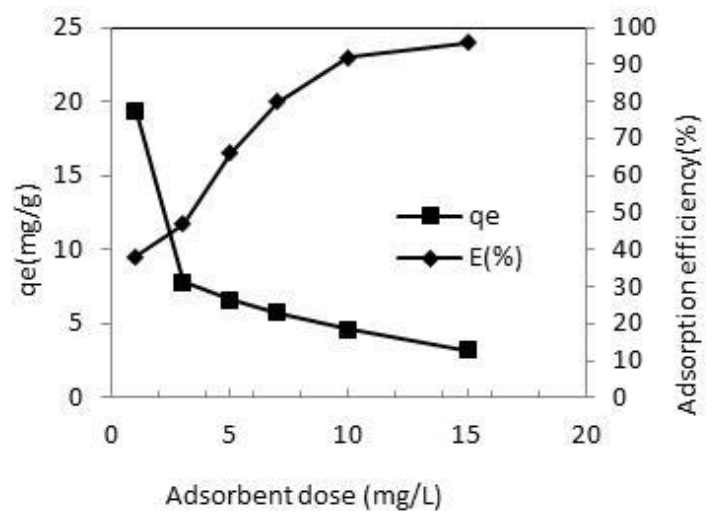

Figure 9. Effect of adsorbent dose on MR GRL adsorption capacity.

Experimental conditions: $[\text { Dye }]_{0}=50 \mathrm{mg} / \mathrm{L}, \mathrm{t}=150 \mathrm{~min}$

As shown in Fig. 10, the removal rate reduces with increasing concentration of MR GRL. Apparently, the initial MR GRL concentration plays an important role in affecting the capacity of MR GRL to absorb onto grape molasses soil.

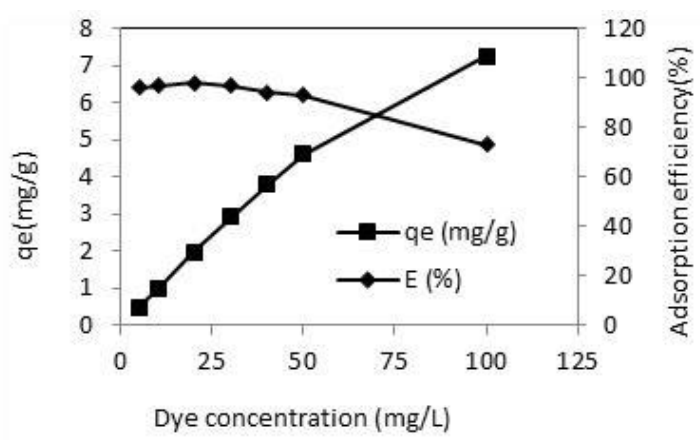

Figure 10. Effect of dye concentration on MR GRL adsorption capacity.

Experimental conditions: [Adsorbent $]_{0}=10 \mathrm{~g} / \mathrm{L}, \mathrm{t}=150 \mathrm{~min}$

The effect of contact time ranges $0-1440 \mathrm{~min}$ on the adsorption of MR GRL by the grape molasses soil is shown in Fig. 11. Based on these results, the extent of removal of MR GRL by adsorbent was found to increase reach a maximum value with increase in contact time, after 120 $\min$.

Particle size of an adsorbent played a very important role in the adsorption capacity of dye (Aljeboree et al., 2014). In order to the effect of particle size of adsorbent on the adsorption of MR GRL, adsorbent dose fixed at $10 \mathrm{~g} / \mathrm{L}$ with particle size in the range $0.075-2 \mathrm{~mm}$ was added to dye solutions and the results are given for removal efficiency (\%) in Fig. 12. It shows minimum particle size showed greater adsorption than larger size. Small size of adsorbent 
increases the surface area for adsorption (Rehman et al., 2013).

According to Fig. 12, the dye removal efficiency was obtained above $90 \%$ at $10 \mathrm{~g} / \mathrm{L}$ adsorbent dose, $50 \mathrm{mg} / \mathrm{L}$ dye concentration and particle size of $<0.075 \mathrm{~mm}$.

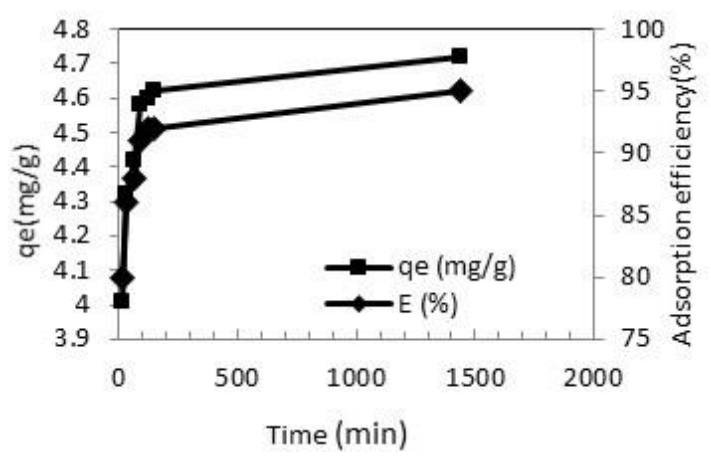

Figure 11. Effect of contact time on MR GRL adsorption capacity.

Experimental conditions: [Dye $]_{0}=50 \mathrm{mg} / \mathrm{L}$,

$[\text { Adsorbent }]_{0}=10 \mathrm{~g} / \mathrm{L}$.

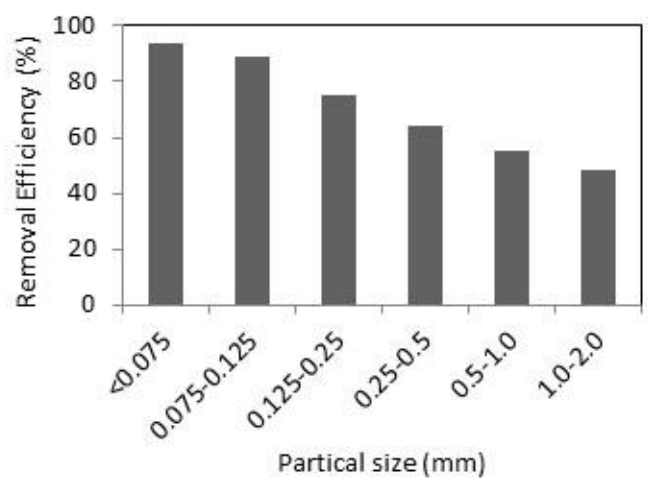

Figure 12. Effect of particle size on MR GRL

Experimental conditions: $[\text { Dye }]_{0}=50 \mathrm{mg} / \mathrm{L}$, [Adsorbent $]_{0}=10$ $\mathrm{g} / \mathrm{L}, \mathrm{T}=30^{\circ} \mathrm{C}, \mathrm{t}=150 \mathrm{~min}$.

Adsorption experiments were carried out for $50 \mathrm{~mL}$ dye solution containing $50 \mathrm{mg} / \mathrm{L}$ at different temperatures 25 , 30 , and $40{ }^{\circ} \mathrm{C}$ using $10 \mathrm{~g} / \mathrm{L}$ of adsorbent in order to follow the effect of temperature on the adsorption of MR GRL(Fig. 13)

In Fig. 13, the results showed that removal efficiencies of initial dye concentration were not changed as temperature from 25 to $40^{\circ} \mathrm{C}$.

The adsorption data were analyzed using adsorption isotherm models, Langmuir and Freundlich. The linearized MR GRL Langmuir and Freundlich adsorption isotherms at different initial dye concentration $(5,10,20,30,40,50,100$ $\mathrm{mg} / \mathrm{L}$ ), at natural $\mathrm{pH}$ of dye solution, temperature $30^{\circ} \mathrm{C}$, and $10 \mathrm{~g} / \mathrm{L}$ adsorbent dose were used to determine the adsorption capacity of grape molasses soil for MR GRL. The adsorption constant evaluated from the isotherms with correlation coefficients are shown in Table 1 . The maximum capacity $Q_{0}$ determined from the Langmuir isotherm defines the total capacity of the grape molasses soil for the dye as $7.686 \mathrm{mg} / \mathrm{g}$ adsorbent. The fact that, compared to Freundlich isotherm, the Langmuir isotherm fits the experimental data due to the homogeneous distribution of active sites on the surface of adsorbent.

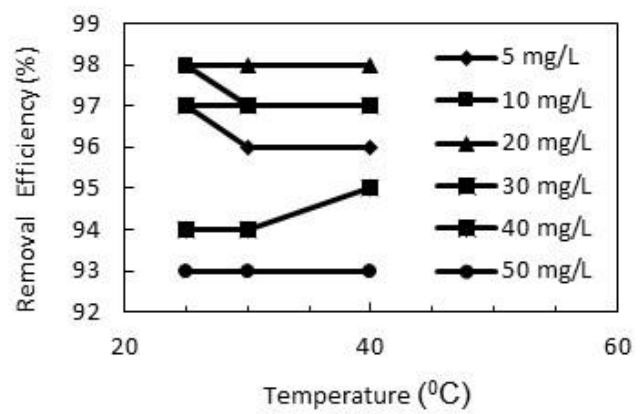

Figure 13. Effect of temperature on MR GRL. Experimental conditions: $[\text { Dye }]_{0}=50 \mathrm{mg} / \mathrm{L}$, [Adsorbent $]_{0}=10 \mathrm{~g} / \mathrm{L}, \mathrm{t}=150$ $\min$.

The Langmuir model is based on the assumption that maximum adsorption corresponds to a saturated monolayer of solute molecules on the adsorbent surface (El-Sayed et al., 2013).

\section{Conclusions}

In this study, the removal of MR GRL from aqueous solutions by adsorption onto raw soil sample known as Niğde (Bor) grape molasses soil and $\mathrm{Fe}^{+2} / \mathrm{H}_{2} \mathrm{O}_{2}$ reagent as advanced treatment processes were studied. The dye removal efficiency was obtained above $90 \%$ at $10 \mathrm{~g} / \mathrm{L}$ adsorbent dosage, $50 \mathrm{mg} / \mathrm{L}$ dye concentration, $30{ }^{\circ} \mathrm{C}$ temperature and particle size of $<0.075 \mathrm{~mm}$, respectively. The results show that grape molasses soil could be used as an effective and low cost material for removal of dyes and color from aqueous solution. The equilibrium data were fitted by the Langmuir and Freundlich isotherm models where the data were slightly better fitted by the Langmuir model for the MR GRL in terms of regression values $\left(R^{2}>\right.$ 0.99 ) and the maximum adsorptive quantity of MR GRL was $7.686 \mathrm{mg} / \mathrm{g}$.

The examined Fenton process was found very efficient for removing MR GRL from aqueous solutions. The optimal operation parameters were: 3.0, 200, 150, $100 \mathrm{mg} / \mathrm{L}, 20$ min and $30{ }^{\circ} \mathrm{C}$ for $\mathrm{pH},\left[\mathrm{H}_{2} \mathrm{O}_{2}\right]_{0},\left[\mathrm{Fe}^{+2}\right]_{0},[\mathrm{MR}]_{0}$, reaction time and temperature, respectively. Under these conditions, 99.4\% decolorization efficiency of MR GRL was found in aqueous solution after 20 min of reaction.

Table 1. Adsorption isotherm parameters for the MR GRL dye solutions

\begin{tabular}{cccc}
\hline Freundlich & $\mathbf{K}_{\mathbf{F}}$ & $\mathbf{n}$ & $\mathbf{R}^{\mathbf{2}}$ \\
\cline { 2 - 4 } & 0.114 & 0.413 & 0.903 \\
\hline \multirow{2}{*}{ Langmuir } & $\mathbf{Q}_{0}(\mathbf{m g} / \mathbf{g})$ & $\mathbf{b}(\mathbf{L} / \mathbf{m g})$ & $\mathbf{R}^{\mathbf{2}}$ \\
\cline { 2 - 4 } & 7.686 & 0.535 & 0.995 \\
\hline
\end{tabular}

\section{Acknowledgments}

The author thanks to Sena Şahin and Merve Uncuoğlu for their contributions during experimental studies. 


\section{References}

Aksu Z. (2005), Application of biosorption for the removal oforganic pollutants: a review, Process Biochem., 40, 997-1026.

Aljeboree A.M., Alshirifi A.N. and Alkaim A.F. (2014), Kinetics and equilibrium study for the adsorption of textile dyes on coconut shell activated carbon, Arabian J. Chem., http://dx.doi.org/10.1016/j.arabjc.2014.01.020(in press).

Almazán-Sánchez P.T., Linares-Hernández P.T., Martínez-Miranda V., Lugo-Lugo V. and Fonseca-Montes de Oca R.M.G. (2014), Wastewater treatment of methyl methacrylate (MMA) by Fenton's reagent and adsorption, Cataly. Today, 220-222, 39-48.

Bouasla C., El-Hadi Samar M. and Ismail, F. (2010), Degradation of methyl violet $6 \mathrm{~B}$ dye by the Fenton process, Desalination, 254, 35-41.

Chiou M.S., Ho P.Y. and Li H.Y. (2004), Adsorption of anionic dyes in acid solutions using chemically cross-linked chitosan beads, Dye Pigm., 60, 69-84.

Daud N.K., Akpan U.G. and Hameed B.H. (2012), Decolorization of Sunzol Black DN concentration in aqueous solution by Fenton oxidation process: effect of system parameters and kinetic study, Des. and Wat. Treat., 37, 1-7.

Doğan M., Karaoğlu M.H. and Alkan M. (2009), Adsorption kinetics of maxilon yellow $4 \mathrm{GL}$ and maxilon red GRL dyes on kaolinite, J. Hazard. Mat., 165, 1142-1151.

El-Sayed G.O., Mohammed T.Y. and Abd-Allah Salama A. (2013), Batch adsorption of Maxilon Red GRL from aqueous solution by natural sugarcane stalks, Hindawi Pub.Corp.ISRN Environ. Chem., Article ID 514154, 1-8.

Ertugay N. and Acar F.N. (2017), Removal of COD and color from Direct Blue 71 azo dye wastewater by Fenton's oxidation: Kinetic study, Arabian J. Chem., 10, S1158-S1163.

Gupta V.K. and Suhas P.A.M. (2009), Application of low-cost adsorbents for dye removal-a review, J. Environ. Manage., 90, 2313-2342.

Hameed B.H. and Lee T.W. (2009), Degradation of malachite green in aqueous solution by Fenton process, J. Hazard. Mat., 164, 468-472.

Hayat H., Mahmood Q., Pervez A., Bhatti Z.A. and Baig S.A. (2015), Comparative decolorization of dyes in textile wastewater using biological and chemical treatment, Sep. and Pur. Techn., 154, 149-153.

Jia Z., Li Z., Ni T. and Li S. (2017), Adsorption of low-cost absorption materials based on biomass (Cortaderia selloana flower spikes) for dye removal: Kinetics, isotherms and thermodynamic studies, J. Molec. Liq, 229, 285-292.

Karaoğlu H.M., Doğan M. and Alkan M. (2009), Removal of cationic dyes by kaolinite, Mic. and Mes. Mat., 122, 20-27.

Kumaria H.J., Krishnamoorthy P., Arumugam T.K., Radhakrishnan S. and Vasudevan D. (2017), An efficient removal of crystal violet dye from waste water byadsorption onto TLAC/Chitosan composite: A novel low cost adsorbent, Int. J. Bio. Mac., 96, 324-333.

Libralato G., Volpi Ghirardini A. and Avezzú F. (2010), How toxic is toxic? A proposal for wastewater toxicity hazard assessment, Ecotoxic. and Environ. Safety, 73, 1602-1611.

Lofrano G., Libralato G., Carotenuto M., Guida M., Inglese M., Siciliano A. and Meriç S. (2016), Emerging concern from shortterm textile leaching: a preliminary ecotoxicological survey, Bull. Environ. Contam. Toxicol., 97(5), 646-652.
Nandi B.K., Goswami A. and Purkait M.K. (2009), Adsorption characteristics of brilliant green dye on kaolin, J. Hazard. Mat., 161, 387-395.

Rehman M.S., Munir M., Ashfaq M., Rashid N., Nazar M.F., Danish M. and Han J. (2013), Adsorption of brilliant green dye from aqueous solution onto red clay, Chem. Eng. J., 228, 54-62.

Schrank S.G., Santos J.N.R., Souza D.S. and Souza E.E.S. (2007), Decolourisation effects of Vat Green 01 textile dye and textile wastewater using $\mathrm{H}_{2} \mathrm{O}_{2} / \mathrm{UV}$ process, J. Photochem. Photobiol. A: Chem., 186, 125-129.

Şahinkaya S. (2013), COD and color removal from synthetic textile wastewater by ultrasound assisted electro-Fenton oxidation process, J. Ind.\& Eng. Chem., 19(2), 601-605.

Weng C.H., Lin Y.T. and Tzeng T.W. (2009), Removal of methylene blue from aqueous solution by adsorption onto pineapple leaf powder, J. Hazard. Mat., 170, 417-424. 